\title{
A Simple Approach for Emission Constrained Economic Dispatch Problems
}

\author{
S. Subramanian \\ Professor \\ Department of Electrical Engineering \\ Annamalai University \\ Annamalainagar, India
}

\author{
S. Ganesan \\ Senior Lecturer \\ Department of Electrical Engineering \\ Annamalai University \\ Annamalainagar, India
}

\begin{abstract}
Economic dispatch is a highly constrained optimization problem in power system encompassing interaction among decision variables. Environmental concerns that arise due to the operation of fossil fired electric generators, transforms classical problem into multiobjective Emission Constrained Economic Dispatch (ECED) problem. The idea behind this problem formulation is to estimate the optimal generation schedule of generating units in such a manner that fuel cost and emission levels are simultaneously minimized. This multi-objective optimization problem is converted into a single objective function using price penalty factor. This paper presents a Sequential Approach with a Matrix Framework (SAMF) for solving ECED of thermal units. This is a maiden attempt has been developed to obtain the optimal dispatches for all achievable load demands of a system in single execution. The feasibility of the proposed method is demonstrated for two standard test systems. Numerical simulation results indicate that the proposed method has close agreement with the recent reports.
\end{abstract}

\section{Keywords}

Economic load dispatch, Emission dispatch, Transmission loss, Sequential approach, Matrix framework.

\section{INTRODUCTION}

The economic dispatch problem in a power system is to determine the optimal combination of power outputs for all generating units which will minimize the total fuel cost while satisfying load and operational constraints. The single objective economic dispatch can no longer be considered alone due to environmental concerns arise from the emissions produced by electric power plants. Hence the purpose of emission constrained economic dispatch problem is to determine the optimal amount of generated power for the generating units in the system by minimizing the fuel cost and emission level simultaneously subject to various system constraints. In ECED problem, emission function is added as a second objective to conventional economic dispatching problems. This assigns a less power to all such generation units having high emission, and thus emission is reduced. The contributions of the electric energy industry to environment pollution raise questions concerning environmental protection and methods of eliminating or reducing pollution from power plants either by design or by operational strategies from power plants. The two primary power plant emissions from a dispatching are sulfur dioxide $\left(\mathrm{SO}_{2}\right)$ and nitrogen oxides (NOx).

The US Air Act Amendments of 1990 mandates that the electric utility industry reduce its $\mathrm{SO}_{2}$ emission. Under the ever strict government regulations on environmental protection, the conventional operation at minimum cost can no longer be the only basis for dispatching electric power. Society demands adequate and secure electricity not only at the cheapest possible price, but also at minimum levels of pollution. The passage of clean air act amendments in 1990 has forced utilities to reduce their $\mathrm{SO}_{2}$ and NOx emissions [1].

In order to satisfy the environmental regulations, emission control has become one of the important operational objectives. Including emissions either in the objective function or treating emissions as additional constraints has been considered in a number of publications. A general formulation based on the Lagrange relaxation method has been presented for solving environmental constrained economic dispatch problem [2]. Lamount and Qbesses were detailed various emission dispatching strategies and solution procedure based on emission shadow prices [3]. Srikrishna and Palanichamy proposed an approach for solving combined economic emission dispatch problem [4]. The authors suggested a method to convert the biobjective function into a single objective function using price penalty factor. Song et al. presented the application of a fuzzy logic controlled genetic algorithm to environmental economic dispatch problems [5]. The authors proposed an improved genetic algorithm with two fuzzy controllers to adaptively adjust the crossover probability and mutation rate during optimization process.

Artificial neural network based methods have also been suggested for solving emission constrained economic dispatch problem due to their accuracy $[6,7]$. The methods such as fuzzy satisfaction maximizing technique [8], hybrid genetic and evolutionary programming technique [9] have also been applied to solve this problem. An interactive fuzzy satisfying approach has been suggested for solving emission constrained economic dispatch problems [10]. The multiobjective problem is transformed into a minmax problem and it is solved to obtain the schedule of generation, through the interactive process the decision maker updates the membership values by considering the current values of the membership functions as well as the objectives. An extended linear Hopfield model has been developed for solving this multiobjective problem [11].

Improved versions of evolutionary programming technique have been developed for solving combined economic emission dispatch problem [12]. Particle swarm optimization is one of the stochastic search technique has been applied to solve various kinds of 
economic dispatch problems [13]. Danaraj et.al reported quadratic programming (QP) method to solve this multi objective optimization problem [14]. The authors linearised the nonlinear constraints by transformation of variables technique and quadratic programming is applied till the convergence is reached. Muralidharan et al. developed a dynamic programming recursive approach for solving emission constrained economic dispatch problem [15]. L.Wang and C.Singh investigated to solve this problem by applying a fuzzified multi objective particle swarm optimization algorithm [16]. Pattern search method has been applied to solve various constrained optimization problems. An approach based on constrained pattern search method has been applied to solve this problem [17].

A generalized equation for finding the optimal generations by simplified recursive approach has been developed to solve the combined economic emission problem [18]. Palanichamy and Sundar Babu suggested a direct method based on mathematical modeling for solving this type of problems [19]. An approach based on modified neo-fuzzy neuron has been developed for online environmental and economic dispatch of generating units in a power system [20]. A fuzzy clustering based particle swarm optimization algorithm has been suggested to solve highly constrained environmental economic dispatch problem [21]. A hybrid approach has been developed for solving combined economic emission dispatch problem [22]. The problem has been solved in two stages. In the first stage, a Non-dominated Sorting Genetic Algorithm II (NSGA II) is employed to approximate the set of Pareto solutions and in the subsequent stage; a MultiAttribute Decision-Making (MADM) approach is adopted to determine the best solution in a deterministic environment with a single decision maker.

In this article, SAMF has been developed for solving emission constrained economic dispatch problem. It is a direct method that provides the best schedule of generation with less mathematical steps and execution time.

\section{PROBLEM FORMULATION}

Optimization of ECED problem can be formulated as,

$$
F_{T}=\min f(F C, E C)
$$

This constrained optimization problem is subjected to a variety of constraints. These include power balance constraints and maximum and minimum generation limits of generating units. These constraints are discussed as follows.

Power balance constraints:

This constraint is based on the principle of equilibrium that the total generation should satisfy the total system demand.

$$
\sum_{i=1}^{n} P_{i}=P_{D}
$$

Generating capacity constraints:

The real power output of each generator has a lower and upper bound so that the generations of generating unit lies within this limit. This inequality can be given as follows. $P_{i, \min } \leq P_{i} \leq P_{i, \max }$
The expected fuel cost FC $(\$ / \mathrm{h})$, which is assumed to be approximated by a quadratic function of the generator real power output Pi can be expressed as

$$
F C=\sum_{i=1}^{n} F_{i}\left(P_{i}\right)=\sum_{i=1}^{n}\left(a_{i} P_{i}^{2}+b_{i} P_{i}+c_{i}\right)
$$

The total emission of generation EC $(\mathrm{Kg} / \mathrm{h})$ can be expressed by a quadratic function as follows.

$$
E C=\sum_{i=1}^{n}\left(d_{i} P_{i}^{2}+e_{i} P_{i}+f_{i}\right)
$$

A multi-objective optimization problem is converted to a single optimization problem by introducing price penalty factor $\mathrm{h}(\$ / \mathrm{Kg})$ as follows.

$$
F_{T}=\sum_{i=1}^{n}\left(a_{i} P_{i}^{2}+b_{i} P_{i}+c_{i}\right)+h_{i}\left(d_{i} P_{i}^{2}+e_{i} P_{i}+f_{i}\right)
$$

This objective function has to satisfy the power balance constraint and the generation capacity constraints. The price penalty factor that coordinates the emission costs with the normal fuel costs. After the introduction of the price penalty factor, the total operating cost of the system is the cost of fuel plus the implied cost of emission. The various methods $[4,15,18]$ have been suggested to calculate price penalty factor and among that the maximum price penalty factor has been chosen for combining cost of fuel plus the implied cost of emission as it offers a very good solution for emission restricted less cost condition [18]. The maximum price penalty factor $\mathrm{h}$ of each generator is the ratio between the fuel cost and emission at its maximum power output.

$$
h_{i \max }=\frac{\left(a_{i} P_{i, \max }^{2}+b_{i} P_{i, \max }+c_{i}\right)}{\left(d_{i} P_{i, \max }^{2}+e_{i} P_{i, \max }+f_{i}\right)} \quad \text { for } \mathrm{i}=1,2, \ldots . \mathrm{n}
$$

\section{SOLUTION METHODOLOGY 3.1 Description of the SAMF}

Sequential approach with matrix framework is proposed for solving emission constrained economic dispatch problems. This is the first method developed to obtain the optimal dispatches for all possible load demands in a system. The demonstration of the solution methodology is presented in this section.

The electric power production in a power plant is allowed to vary from minimum technical limit $\left(\mathrm{P}_{\min }\right)$ to maximum technical limit $\left(\mathrm{P}_{\max }\right)$. Initially the $\mathrm{P}_{\mathrm{i}, \mathrm{min}}$ of all generating units in a power plant are considered as initial state input values and is represented by a single dimensional matrix as,

$$
s=\left[\begin{array}{lll}
P_{1, \min } & P_{2, \min } P_{3, \min }, \ldots, P_{n, \min }
\end{array}\right]
$$

Based on the above single dimensional matrix, a square matrix (I) is developed to identify the economic schedule of generation. The formation of the square matrix is as follows. The process starts with a step increment in generation by $\Delta \mathrm{MW}$ in $\mathrm{P}_{1, \min }$ by keeping the remaining units at its input value. This will form first row of the square matrix.

$I_{1}=\left[P_{1, \text { min }}+\Delta P_{2, \text { min }} P_{3, \text { min }}, \ldots, P_{n, \text { min }}\right]$

The increment in generation is made in the second element by 
keeping the other elements at its input value that leads to the development of second row of the square matrix.

$$
I_{2}=\left[P_{1, \text { min }} P_{2, \text { min }}+\Delta P_{3, \text { min }}, \ldots, P_{n, \text { min }}\right]
$$

In the same logic, an increment is made for remaining units one at a time and a square matrix with a dimension equal to the number of units has been developed. For every step increment in the operating range of the plant the unit one at a time is allowed to experience the change in generation thus leads to the formation of the square matrix.

$$
I=\left[\begin{array}{c}
I_{1} \\
I_{2} \\
\cdot \\
I_{n}
\end{array}\right]=\left[\begin{array}{cccc}
P_{1, \text { min }}+\Delta & P_{2, \text { min }} & \ldots & P_{n, \text { min }} \\
P_{1, \text { min }} & P_{2, \text { min }}+\Delta & \ldots & P_{n, \text { min }} \\
\cdot & \cdot & \cdot & \cdot \\
P_{1, \text { min }} & P_{2, \text { min }} & \ldots & P_{n, \text { min }}+\Delta
\end{array}\right]
$$

Each element in the square matrix represents the generation of a unit corresponding to the column that should satisfy the unit capacity constraints.

In the square matrix the unit generations of each row that satisfy the constraints are identified and total fuel cost of generation is evaluated. The desired economic schedule of generation is identified by analyzing fitness of each row. The fitness function of each row is calculated as,

$$
f i t(j)=\frac{F_{T}(j)}{(p d+\Delta)} \quad j=1,2, . . n
$$

Where, pd is the total of input values.

The schedule with the minimum fitness is chosen as the successive state input values. This process is repeated till all the generating units reach their maximum generation capacity. The feasible solutions for every increment from $P_{\min }$ to $P_{\max }$ are obtained and hence the best solution for any load demand falls in the operating boundary can be easily sited.

The detailed computational flow of the proposed method is presented in Fig. 1. The proposed methodology in the form of matrix framework to support the demonstration is as follows.

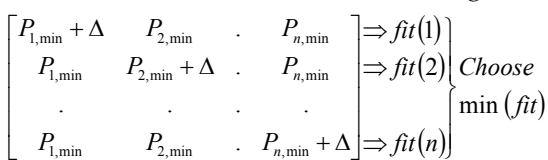

$$
\begin{aligned}
& \downarrow
\end{aligned}
$$

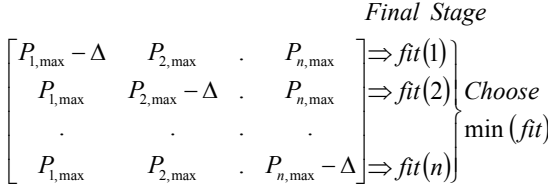

\section{SIMULATION RESULTS AND DISCUSSIONS}

The objective of this multi objective optimization problem is to determine the optimal generations of thermal units in the system by minimizing the fuel cost and emission level simultaneously subject to various system constraints. By introducing price penalty factor multiobjective optimization problem can be converted into a single objective optimization problem and in this article maximum price penalty factor $\left(\mathrm{h}_{\text {imax }}\right)$ is considered. The effectiveness of the proposed approach has been analyzed with two different scale of power system.

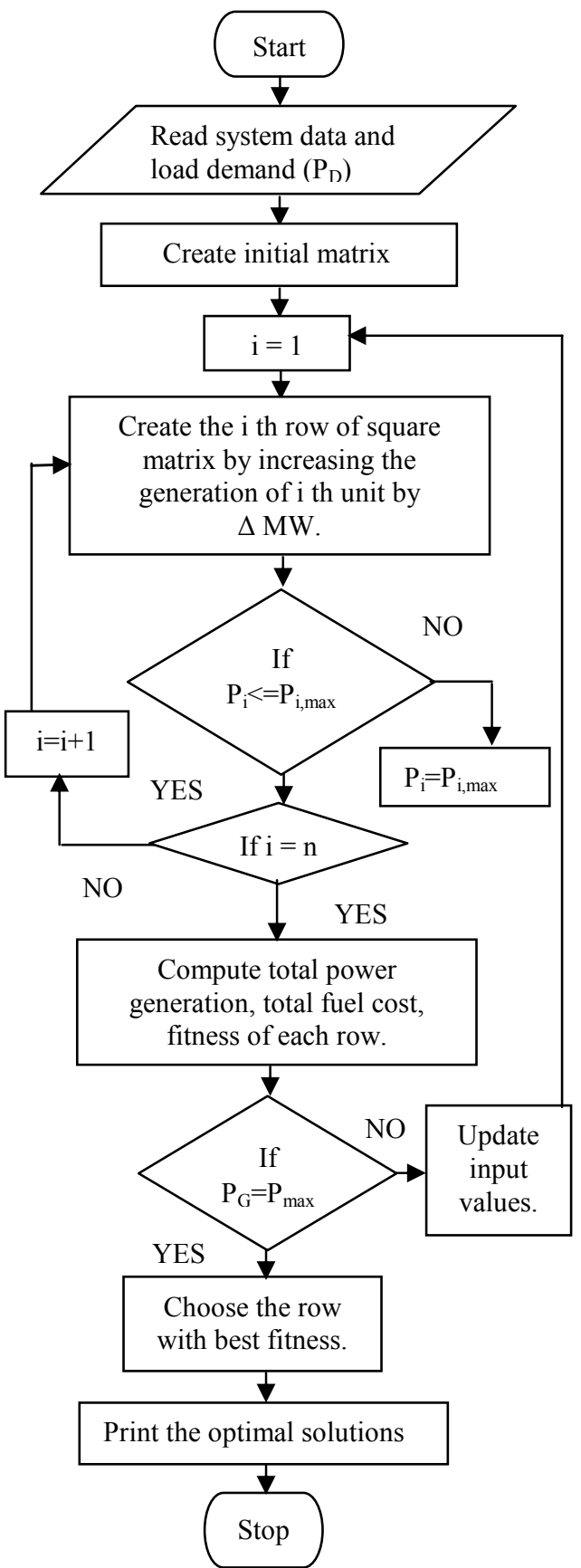

Fig 1 Computational flow of SAMF

The SAMF provides the optimal schedule of generations for all possible load demands which is varied from minimum technical limit by a small increment to maximum technical limit of the system. The selection of increment is also an important factor. 
Too large increment may end up with unfeasible solution and too small increment may take long execution time. Based on experience, the desired increment is chosen as $1 \mathrm{MW}$.

Though the proposed SAMF offers optimum generations for all achievable loads, for the sake of comparison a particular load demand is considered and the simulation results are compared with the earlier techniques available in the literature. The algorithms for solving the examples were implemented in Matlab 7.0 platform and executed with Pentium IV, $2.4 \mathrm{GHz}$ personal computer.

\subsection{Case I: Six unit system}

The details of cost coefficients, emission coefficients and minimum and maximum generations of six unit sample system are presented in the literature [18]. The minimum generations of thermal units are considered as initial state variables and the load is varied from $345 \mathrm{MW}$ to $1350 \mathrm{MW}$. The optimum generations for each load have been determined from the initial state variables by sequential approach. The optimum generations, total emissions and total fuel cost for various load demands (from 500 MW to $1100 \mathrm{MW}$ ) are presented in Table 1 . The results are compared with $\lambda$-iteration method [15], Recursive method [15], Particle Swarm Optimization (PSO) [18], Differential Evolution (DE) [18] and Simplified Recursive (SR) method [18] and the comparisons are detailed in Tables 2 and 3. It is noticeable that the results are competitions with the earlier reports. The comparisons of results are evident that the proposed approach offers the solution and which has close agreement with the $\lambda$ iteration method.

\subsection{Case II: Eleven unit system}

The particulars of cost coefficients, emission coefficients and minimum and maximum generations of eleven unit sample system are given in the literature [18]. The load is varied from $640 \mathrm{MW}$ to $3570 \mathrm{MW}$. The optimum generations for each load have been determined from the initial state variables by sequential approach. The optimum generations, emissions and total fuel cost for various load demands from $1000 \mathrm{MW}$ to $2500 \mathrm{MW}$ are presented in Table 4. The results are compared with $\lambda$-iteration method [15], Recursive method [15], Particle Swarm Optimization (PSO) [18], Differential Evolution (DE) [18] and Simplified Recursive (SR) method [18] and the comparisons are tabulated in Tables 5 and 6. From these comparisons of results, it is clear that the proposed approach yields the solutions that are accordance with the solutions by $\lambda$-iteration method.

For most of the load demands, the proposed method yields better results and they are in good agreement with the existing methods. The economic and environmental dispatch is conflicting multiobjective problem when the fuel cost increases the emission level decreases and hence in vice versa. As per the above statement, for some load conditions, there is a slight deviation in cost and emission with respect to the other existing methods.

The computational time of the proposed approach for various test systems has been presented in Table 7. This methodology directly yields the optimum generations for all possible loads in a single execution.

The proposed methodology, SAMF has following merits.

- $\quad$ From these inquiries, this approach has the competence to provide high eminence solution over the existing optimization techniques.

- The performance of the proposed process is independent of the number of generating units in the system hence suitable for system of any size.

- It is a direct method that provides the optimal solution for all achievable load demands in a single run.

- The computational procedure is minimal.

Table 1 Simulation results of six unit system

\begin{tabular}{c|c|c|c|c|c|c|c|c}
\hline $\begin{array}{c}\text { Load } \\
(\mathrm{MW})\end{array}$ & $\begin{array}{c}\text { Unit1 } \\
(\mathrm{MW})\end{array}$ & $\begin{array}{c}\text { Unit 2 } \\
(\mathrm{MW})\end{array}$ & $\begin{array}{c}\text { Unit 3 } \\
(\mathrm{MW})\end{array}$ & $\begin{array}{c}\text { Unit 4 } \\
(\mathrm{MW})\end{array}$ & $\begin{array}{c}\text { Unit 5 } \\
(\mathrm{MW})\end{array}$ & $\begin{array}{c}\text { Unit 6 } \\
(\mathrm{MW})\end{array}$ & $\begin{array}{c}\text { Fuel cost } \\
(\$ / \mathrm{h})\end{array}$ & $\begin{array}{c}\text { Emission } \\
\text { output } \\
(\mathrm{Kg} / \mathrm{h})\end{array}$ \\
\hline 500 & 20 & 15 & 93 & 90 & 144 & 138 & 27092.57 & 261.6278 \\
\hline 600 & 32 & 29 & 108 & 104 & 166 & 161 & 31632.04 & 338.7412 \\
\hline 700 & 44 & 42 & 124 & 118 & 189 & 183 & 36314.52 & 434.2816 \\
\hline 800 & 55 & 56 & 139 & 132 & 212 & 206 & 41144.66 & 547.9645 \\
\hline 900 & 67 & 70 & 154 & 146 & 235 & 228 & 46133.46 & 679.0922 \\
\hline 1000 & 79 & 84 & 170 & 159 & 258 & 250 & 51274.26 & 828.2829 \\
\hline 1100 & 90 & 98 & 185 & 173 & 281 & 273 & 56548.33 & 996.1828 \\
\hline
\end{tabular}


Table 2 Total fuel cost comparison of Case I

\begin{tabular}{c|c|c|c|c|c|c}
\hline \multirow{2}{*}{$\begin{array}{c}\text { Load } \\
(\mathrm{MW})\end{array}$} & \multicolumn{7}{|c|}{$\begin{array}{c}\text { Fuel cost }(\$ / \mathrm{h}) \\
\text { method }\end{array}$} & $\begin{array}{c}\text { Recursive } \\
\text { method }[15]\end{array}$ & PSO [18] & DE [18] & SR [18] & SAMF \\
\hline 500 & 27092.5 & 27092.5 & 27097.5 & 27098.1 & 27092.5 & $\mathbf{2 7 0 9 2 . 5 7}$ \\
\hline 600 & 31628.7 & 31628.6 & 31634.9 & 31629.7 & 31628.6 & $\mathbf{3 1 6 3 2 . 0 4}$ \\
\hline 700 & 36314.0 & 36313.9 & 36314.2 & 36314.0 & 36313.9 & $\mathbf{3 6 3 1 4 . 5 2}$ \\
\hline 800 & 41148.4 & 41148.3 & 41160.3 & 41152.6 & 41148.3 & $\mathbf{4 1 1 4 4 . 6 6}$ \\
\hline 900 & 46131.8 & 46131.8 & 46160.6 & 46132.1 & 46131.8 & $\mathbf{4 6 1 3 3 . 4 6}$ \\
\hline 1000 & 51264.6 & 51264.5 & 51269.6 & 51264.5 & 51264.5 & $\mathbf{5 1 2 7 4 . 2 6}$ \\
\hline 1100 & 56546.4 & 56546.2 & 56546.7 & 56546.2 & 56546.2 & $\mathbf{5 6 5 4 8 . 3 3}$ \\
\hline
\end{tabular}

Table 3 Total emission comparison of Case I

\begin{tabular}{c|c|c|c|c|c|c}
\hline \multirow{2}{*}{$\begin{array}{c}\text { Load } \\
(\mathrm{MW})\end{array}$} & \multicolumn{7}{|c}{ Total emission $(\mathrm{Kg} / \mathrm{h})$} \\
\cline { 2 - 7 } & $\begin{array}{c}\lambda \text {-iteration } \\
\text { method }\end{array}$ & $\begin{array}{c}\text { Recursive } \\
\text { method }[15]\end{array}$ & PSO [18] & DE [18] & SR [18] & SAMF \\
\hline 500 & 261.635 & 261.634 & 262.225 & 261.859 & 261.634 & $\mathbf{2 6 1 . 6 2 7 8}$ \\
\hline 600 & 338.993 & 338.992 & 339.820 & 339.065 & 338.992 & $\mathbf{3 3 8 . 7 4 1 2}$ \\
\hline 700 & 434.380 & 434.380 & 434.605 & 434.453 & 434.380 & $\mathbf{4 3 4 . 2 8 1 6}$ \\
\hline 800 & 547.797 & 547.796 & 547.844 & 547.802 & 547.796 & $\mathbf{5 4 7 . 9 6 4 5}$ \\
\hline 900 & 679.241 & 679.241 & 679.724 & 679.283 & 679.241 & $\mathbf{6 7 9 . 0 9 2 2}$ \\
\hline 1000 & 828.720 & 828.715 & 828.863 & 828.715 & 828.715 & $\mathbf{8 2 8 . 2 8 2 9}$ \\
\hline 1100 & 996.224 & 996.218 & 996.672 & 996.222 & 996.218 & $\mathbf{9 9 6 . 1 8 2 8}$ \\
\hline
\end{tabular}

Table 4 Simulation results of eleven unit system

\begin{tabular}{c|c|c|c|c|c|c|c}
\hline \multirow{2}{*}{ Unit } & \multicolumn{7}{|c}{ Load demand (MW) } \\
\cline { 2 - 7 } & 1000 & 1250 & 1500 & 1750 & 2000 & 2250 & 2500 \\
\hline 1 & 86 & 95 & 104 & 113 & 122 & 131 & 140 \\
\hline 2 & 77 & 83 & 89 & 95 & 101 & 107 & 113 \\
\hline 3 & 87 & 97 & 107 & 117 & 126 & 136 & 146 \\
\hline 4 & 78 & 102 & 126 & 150 & 174 & 198 & 221 \\
\hline 5 & 48 & 63 & 77 & 92 & 107 & 122 & 137 \\
\hline 6 & 79 & 102 & 126 & 149 & 172 & 195 & 219 \\
\hline 7 & 50 & 65 & 80 & 95 & 110 & 125 & 140 \\
\hline 8 & 130 & 165 & 201 & 237 & 273 & 309 & 345 \\
\hline 9 & 122 & 157 & 191 & 226 & 261 & 295 & 329 \\
\hline 10 & 120 & 160 & 201 & 241 & 282 & 323 & 364 \\
\hline 11 & 123 & 161 & 198 & 235 & 272 & 309 & 346 \\
\hline
\end{tabular}


Table 5 Total fuel cost comparison of Case II

\begin{tabular}{|c|c|c|c|c|c|c|}
\hline \multirow[b]{2}{*}{ Load (MW) } & \multicolumn{6}{|c|}{ Fuel cost $(\$ / h)$} \\
\hline & $\begin{array}{c}\lambda \text {-iteration } \\
\text { method }\end{array}$ & $\begin{array}{c}\text { Recursive } \\
\text { method [15] }\end{array}$ & PSO [18] & $\mathrm{DE}[18]$ & SR [18] & SAMF \\
\hline 1000 & 8502.8 & 8502.29 & 8508.24 & 8505.81 & 8502.29 & 8502.875 \\
\hline 1250 & 9108.38 & 9108.38 & 9114.42 & 9117.63 & 9108.38 & 9109.206 \\
\hline 1500 & 9733.54 & 9733.54 & 9737.33 & 9736.22 & 9733.54 & 9734.474 \\
\hline 1750 & 10377.78 & 10377.78 & 10380.82 & 10377.86 & 10377.78 & 10378.92 \\
\hline 2000 & 11041.08 & 11041.08 & 11041.09 & 11041.08 & 11041.08 & 11041.56 \\
\hline 2250 & 11723.47 & 11723.47 & 11725.68 & 11723.54 & 11723.47 & 11724.15 \\
\hline 2500 & 12424.94 & 12424.94 & 12425.06 & 12425.06 & 12424.94 & 12425.85 \\
\hline
\end{tabular}

Table 6 Total emission comparison of Case II

\begin{tabular}{|c|c|c|c|c|c|c|}
\hline \multirow[b]{2}{*}{ Load (MW) } & \multicolumn{6}{|c|}{ Total emission $(\mathrm{Kg} / \mathrm{h})$} \\
\hline & $\begin{array}{c}\lambda \text {-iteration } \\
\text { method }\end{array}$ & $\begin{array}{l}\text { Recursive } \\
\text { method [15] }\end{array}$ & PSO [18] & $\mathrm{DE}[18]$ & SR [18] & SAMF \\
\hline 1000 & 205.205 & 205.204 & 208.012 & 205.206 & 205.204 & 204.8865 \\
\hline 1250 & 339.870 & 339.870 & 345.669 & 339.935 & 339.870 & 339.3336 \\
\hline 1500 & 540.545 & 540.544 & 545.307 & 544.298 & 540.544 & 540.0017 \\
\hline 1750 & 807.220 & 807.220 & 812.863 & 807.236 & 807.220 & 806.2654 \\
\hline 2000 & 1139.912 & 1139.911 & 1142.182 & 1139.911 & 1139.911 & 1139.632 \\
\hline 2250 & 1538.600 & 1538.600 & 1540.465 & 1538.659 & 1538.600 & 1537.867 \\
\hline 2500 & 2003.301 & 2003.301 & 2009.720 & 2003.350 & 2003.301 & 2001.959 \\
\hline
\end{tabular}

Table 7 Execution time (s) of Case I and Case II

\begin{tabular}{c|c}
\hline Test system & Execution time (s) \\
\hline 6 & 0.2613 \\
\hline 11 & 0.8803 \\
\hline
\end{tabular}

\section{CONCLUSION}

This paper presents a new methodology, sequential approach with a matrix frame work for solving emission constrained economic dispatch of thermal units. The multiobjective optimization problem has been converted into a single objective optimization problem by introducing the price penalty factor. In this article maximum price penalty factor is considered as it offers a high-quality solution for emission restricted less cost condition. The minimum generations are treated as initial state variables and the load is increased from minimum to maximum technical limit of the system. It is a direct method that affords the optimal generations dispatch for all achievable load demand of the system in single execution. The performance of the proposed methodology is validated with two standard test systems. The simulation results reveal that the proposed approach has competence to offer the high quality solution and the search process is independent of the system size hence the proposed SAMF is suitable for system of any size.

\section{ACKNOWLEDGEMENT}

The authors gratefully acknowledge the management the support and facilities provided by the authorities of Annamalai University, Annamalainagar, India to carry out this research work.

\section{REFERENCES}

[1] IEEE Current Operating Problems Working Group, Potential impacts of clean air regulations on system operations, Vol. 10, pp 647-653, 1998.

[2] El-keib, A.A., Ma, H. and Hart, J.L. 1994. Environmentally constrained economic dispatch using a Lagrangian relaxation method. IEEE Trans. Power Systems. 9, 4, 1723-1729.

[3] Lamont, M.W. and Qbessis, E.V. 1995. Emission dispatch models and algorithms for the 1990's. IEEE Trans. Power Systems. 10, 2, 941-947.

[4] Srikrishna, K. and Palanichamy, C. 1991. Economic thermal power dispatch with emission constraint. J. Institution. Engineers. (India), 72, 11-18. 
[5] Song, Y.H., Wang, G.S., Wang, P.Y. and Johns, A.T. 1997. Environmental/economic dispatch using fuzzy logic controlled genetic algorithms. IEE Proc. Generation, Transmission and Distribution. 144, 4, 377 -382.

[6] Singh, G., Srivastava, S.C., Kalra, P.K. and Vinoth Kumar, D.M. 1995. Fast approach to artificial neural network training and its application to economic load dispatch. Electrical Machines and Power Systems. 13-24.

[7] Su, C.T. and Chiou, G.J. 1997. A fast computation Hopfield method to economic load dispatch of power systems. IEEE Trans. Power System. 12, 4, 1759 -1764.

[8] Haung, C.M, Yang, H.T. and Huang, C.L. 1997. Biobjective power dispatch using fuzzy satisfaction maximizing decision approach. IEEE Trans. Power Systems. 12, 4, 1715-1721.

[9] Wong, K.P. and Yuryevich, J. 1998. Evolutionary programming based algorithm for environmentally constrained economic dispatch. IEEE Trans. Power Systems. 13, 2, 301-309.

[10] Hota, P.K., Chakrabarti, R. and Chattopadhyay, P.K. 2000. Economic emission load dispatch through an interactive fuzzy satisfying method. Electric Power System Research. 54, 151-157.

[11] Chiou, G.-J. and Su, C.-T. 2000. Economic dispatching with prohibited zones using an extended linear Hopfield model. European Trans. Electrical Power, 10, 2, 113-118.

[12] Jayabarathi, T., Jayaprakash, K., Jayakumar, D. N. and Raghunathan, T. 2005. Evolutionary programming techniques for different kinds of economic dispatch problems. Electric Power Systems Research. 73,169-176.

[13] Jeyakumar, D.N., Jayabharathi, T. and Raghunathan, T. 2006. Particle swarm optimization for various types of economic dispatch problems. Int. J. Electrical Power. Energy Systems. 28, 36-42.

[14] Danaraj, R.M.S. and Gajendran, F. 2005. Quadratic programming solution to emission and economic dispatch problems. J. Institution of Engineers (India). 86, 129-132.
[15] Muralidharan, S., Srikrishna, K. and Subramanian, S. 2006. Emission constrained economic dispatch - A new recursive approach. Electric Power Components and Systems. 34, 343-353.

[16] Wang, L. and Singh, C. 2007. Environmental/economic power dispatch using a fuzzified multi-objective particle swarm optimization algorithm. Electric Power Systems Research. 77,1654-1664.

[17] AL-Sumait, J.S., Sykulski, J.K. and L-Othman, A.K. 2008. Solution of different types of economic dispatch problems using pattern search method. Electric Power Components and Systems. 36, 250-265.

[18] Balamurugan, R. and Subramanian, S. 2008. A simplified recursive approach to combined economic emission dispatch. Electric Power Components and Systems. 36, 1727.

[19] Palanichamy, C. and Sundar Babu, N. 2008. Analytical solution for combined economic and emissions dispatch. Electric Power Systems Research. 78, 1129-1137.

[20] Krishna Teerth Chaturvedi, Manjaree Pandit, and Laxmi Srivstava. 2008. Modified neo-fuzzy neuron based approach for economic and environmental optimal power dispatch. Applied Soft Computing. 8, 1428-1438.

[21] Shubham Agrawal, Panigrahi, B.K. and Manoj Kumar Tiwari. 2008. Multiobjective particle swarm algorithm with fuzzy clustering for electrical power dispatch. IEEE Trans. Evolutionary Computation. 12, 15, 529-541.

[22] Li Xuebin. 2009. Study of multi-objective optimization and multi-attribute decision-making for economic and environmental power dispatch. Electric Power Systems Research. 79, 789-795. 